\title{
Iron manganese ores comprehensive processing
}

\author{
Margarita Gurman ${ }^{1 *}$ \\ ${ }^{1}$ Mining Institute of Far eastern branch of Russian Academy of Sciences, Khabarovsk city, Russia
}

\begin{abstract}
This article illustrates the results of the study of leaching the resistant industrial products of manganese with the subsequent deposit of Mn from the solution with ammonia and hydrogen peroxide oxidizer. The chemical beneficiation of industrial products under optimal conditions aids in converting 96-98\% manganese and its attendant iron into concentrates (in the form of sediments) containing 30.53-40.44\% $\mathrm{Mn}$ and $10-15 \% \mathrm{Fe}$, sludge cakes containing 80.36-83.81\% $\mathrm{SiO}_{2}$. It shows that the use of hydrometallurgy in combination with the beneficiation of hematitebraunite ores using gravity and magnetic radiation aids in the $10.39 \%$ increase of total manganese recovery in mineral form, (with 76-87.19\% increase in chemical form) and allows for integrated use of valuable components. Key words: hematite-braunite ores, resistant industrial products of manganese, acid leaching, deposits, manganese extraction, combined scheme.
\end{abstract}

\section{Introduction}

Over ten minor mineral deposits of manganese are known on the territory of the Far East, and the largest of them (with balance stocks of manganese ores 6.53 million tons) is the Poperechnoye deposit, which is part of South Khingan deposit. The studies of the material composition and beneficiation capacity of the manganese ores in the Poperechnoye deposit were held in the 1950's (Chebotarev M.V, Chebotareva N.A., Suvorov F.S., Shchugol S.D., Toropkov S.D.). Previously obtained data on the ores are nowadays complemented with geochemical, petrographic, mineralogical and technological studies involving present-day physical-chemical methods [2-6]. As a result of iron manganese ores analyses, that were held in the Institute of Mining of Far East Division of Russian Academy of Sciences, it was found that ores are resistant to beneficiation. They are characterized by the complex microand finely banded texture of layers, besides having uneven alteration of hollow rocks and layers of ore, finely imbedded dispersive granularity of the braunite, hematite and magnetite in jaspilites, their intergrowth with the minerals of the hollow rocks, the similarity of the physical properties of separable minerals, and the low content of metals. The ore was found to have precious metal mineralization, characterized by pure gold and its thin spots, mixed with platinum and silver in the magnetite and hematite jaspilites. Combining the methods of magnetic separation (in low field and high field) and ore

${ }^{*}$ Corresponding author: mgurman@yandex.ru 
beneficiation by gravity, based on the concentration of pure gold, illustrates the possibility to obtain manganese concentrates containing 37.85-46.46 \% $\mathrm{Mn}$ and golden "heads" containing 12.76-37.17 g/ton Au. The process of ore beneficiation by gravity and magnetic radiation has generated the industrial products (with low content of manganese, but having a large amount of quartz), that can be fully developed based on the chosen scheme. Manganese ore decomposition is known to be achieved by means of processing the ore with $\mathrm{HCl}, \mathrm{HBr}, \mathrm{H}_{2} \mathrm{SO}_{4}, \mathrm{HNO}_{3}$ or their mixtures depending on the mineral form of the manganese, which will interact with certain reagent $[8,9]$. This research was held for the purpose of conducting the acid leaching of resistant industrial products of manganese with subsequent extraction of manganese from the solution.

\section{Research techniques}

The research was focused on the resistant industrial products of gravitational and magnetic beneficiation of the hematite-braunite ores containing 11.7-32.1 \& manganese. The industrial products were presented by the braunite, its intergrowth, its parts attached to quartz and hematite, hematite jaspilites with crystal spots and the thin layers of braunite; magnetite jaspilites with spots of thin-scaled hematite. According to the X-Ray diffraction analysis data, braunite is basically present in the form of $\mathrm{Mn}_{2} \mathrm{O}_{3}$ and $\mathrm{Mn}_{2} \mathrm{O}_{3} \cdot \mathrm{MnSiO}_{3}$. Braunite modifications were revealed - $\mathrm{CaMn}_{14} \mathrm{SiO}_{24}$ и $(\mathrm{MnFeCa})_{7}(\mathrm{SiFe}) \mathrm{O}_{12}$, with tephroite - $\mathrm{Mn}_{2} \mathrm{SiO}_{4}$ and bixbyite $-(\mathrm{Mn}, \mathrm{Fe}) \mathrm{MnO}_{3}$ as well.

Manganese mineral oxides are dissolved in hydrochloric acid, which is the dissolvent for the attendant mineral oxides of iron, aluminum. The manganese and iron, resultant from this reaction, are turned into a solution, and the insoluble sediment of silicon dioxide remains in the sludge cakes of leaching. The extraction of manganese out of the solution was implemented by means of precipitation in the form of hydrated oxides in the solution of ammonia mixed with hydrogen peroxide $[8,10]$. The addition of $\mathrm{H}_{2} \mathrm{O}_{2}$ accelerates oxidation [11], while the sediment is immediately turned into a brown-black hydrated manganese dioxide. The iron and aluminum, present in the solution, are precipitated together with the manganese. For the separation of alkaline earth metals that can also be attracted to the manganese sediment the manganese was subject to reprecipitation.

\section{Results and discussion}

According to the obtained data, hydrometallurgical processing of manganese industrial products (sample 1-3) allows for the conversion of 95-98.8\% manganese and iron into a concentrate (in the form of sediment) with its 57.43-76.82\% output (pic 2). Test 1, containing 29.8-32.1 \% manganese, 7.9-8.4\% iron and $18.62-20.77 \% \mathrm{SiO}_{2}$, resulted in the concentrate containing 39.1-41.8 \% Mn и 10.4-10.7\% Fe with its residual content of $0.64-$ $1.45 \% \mathrm{SiO}_{2}$. Test 2, containing 17.6-18.1\% Mn, 9-9.3\% Fe и 33.19-36.34 \% $\mathrm{SiO}_{2}$, led to the extraction of the concentrates containing 30.1-32,1\% Mn, 15,1-17.5\% Fe with its residual content of $\mathrm{SiO}_{2}-0.64-1.28 \%$. Test 3: $\mathrm{Mn}-11.7-12.6 \%, \mathrm{Fe}-8-9 \%$ iron, $\mathrm{SiO}_{2}-$ $34.05-35.97 \%$ resulted the concentrates with lower content of $\mathrm{Mn}-20-22.3 \%$ и $10.3-10.6$ $\% \mathrm{Fe}$ with its residual content of $\mathrm{SiO}_{2}-1.34-2.78 \%$. 


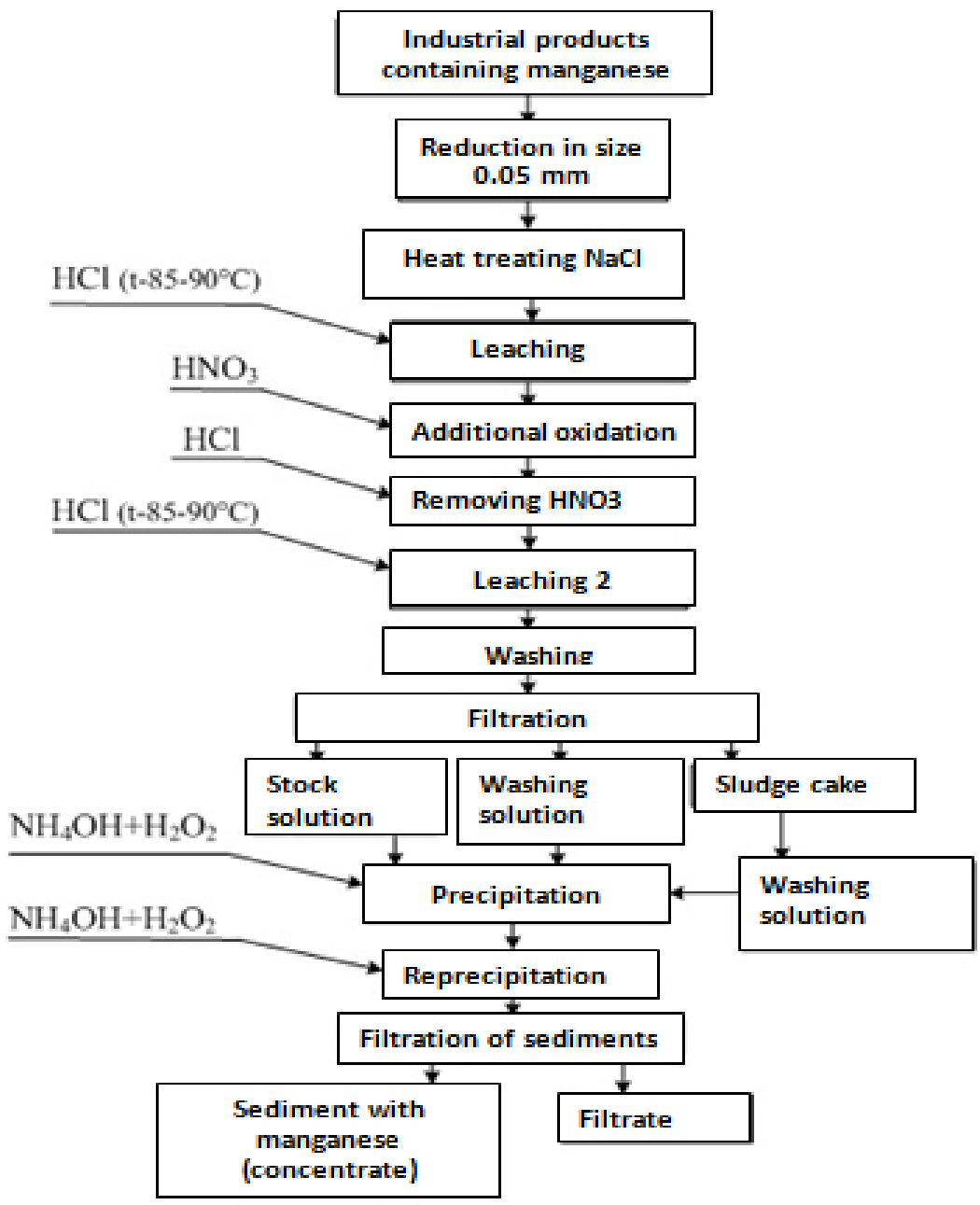

Fig. 1. Hydrometallurgical scheme of processing industrial products of hematite-braunite ore beneficiation. 

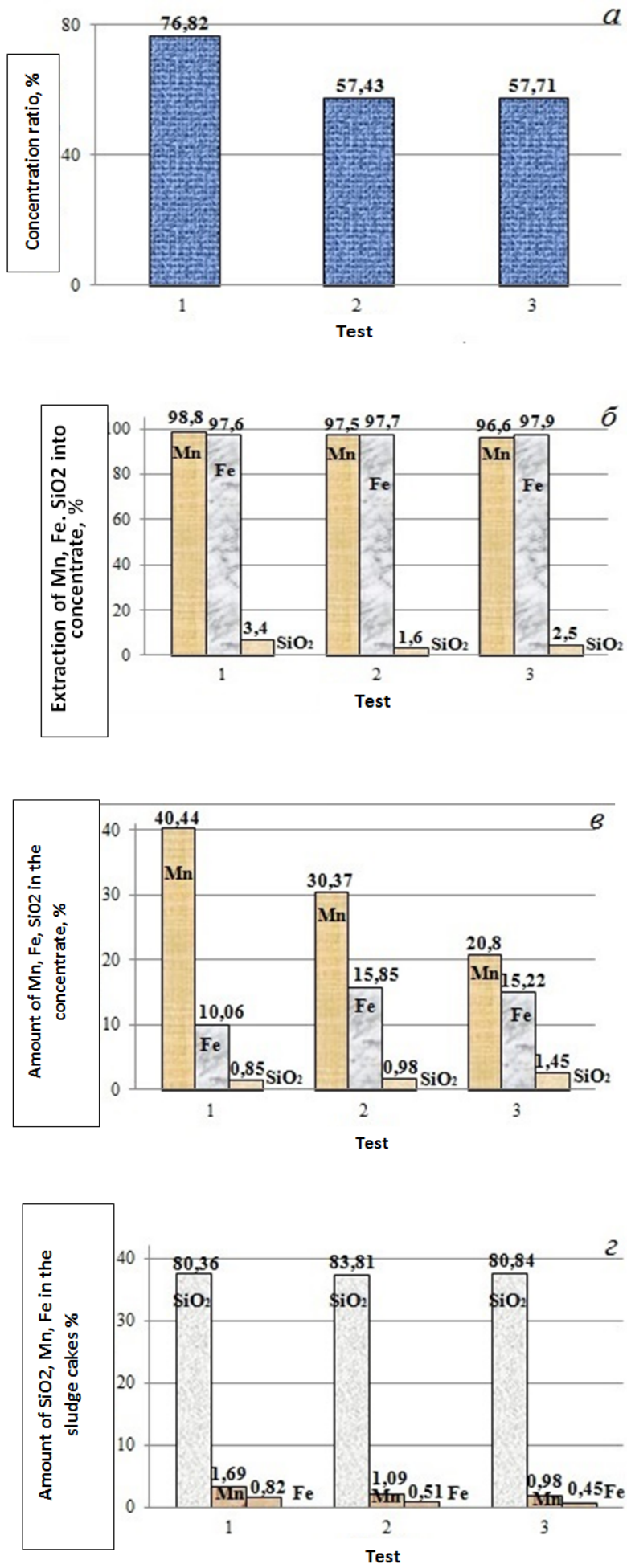

Fig. 2. Technological rates of processing industrial products. 
Table 1. Rates of extracting manganese in mineral [7] and chemical form under the combination of beneficiation and hydrometallurgy techniques.

\begin{tabular}{|c|c|c|c|c|}
\hline The name of the products & $\begin{array}{c}\text { Output, } \\
\%\end{array}$ & \multicolumn{2}{|c|}{ Contents, $\mathrm{Mn}, \mathrm{Fe}$} & $\begin{array}{l}\text { Extraction } \\
\text {, Mn, \% }\end{array}$ \\
\hline \multicolumn{5}{|c|}{ Wet magnetic separation } \\
\hline Concentrate 1 & 11.43 & 44.31 & 6.82 & 23.69 \\
\hline Concentrate 2 & 0.41 & 37.05 & 5.02 & 0.71 \\
\hline Total amount of concentrate & 11.84 & \multicolumn{2}{|c|}{-} & 24.40 \\
\hline Semiproduct & 2.71 & 16.96 & 8.35 & 2.15 \\
\hline \multicolumn{5}{|c|}{ Jigging - centrifugal separation $\mathrm{Kn}$ - concentration on the table } \\
\hline Concentrate jigging - table & 1.35 & 37.00 & 6.47 & 2.33 \\
\hline Concentrate $\mathrm{Kn}-$ table & 1.74 & 38.71 & 6.77 & 3.15 \\
\hline Reduction concentrate $-\mathrm{Kn}-$ table & 4.89 & 41.23 & 6.54 & 9.43 \\
\hline $\begin{array}{l}\text { Total gravitation concentrate } \\
\text { including the head of the table, } \mathrm{Au} \text {, } \\
\mathrm{g} / \mathrm{ton}\end{array}$ & $\begin{array}{l}7.98 \\
0.50\end{array}$ & $\begin{array}{l}39.95 \\
12.76- \\
37.17\end{array}$ & 6.52 & 14.91 \\
\hline Industrial product & 14.94 & 29.19 & 6.53 & 20.40 \\
\hline Tailings & 62.53 & 13.04 & 6.45 & 38.14 \\
\hline \multicolumn{5}{|c|}{ Dry magnetic separation } \\
\hline Concentrate $-1+0.5 \mathrm{MM}$ & 2.86 & 47.10 & 3.81 & 6.30 \\
\hline Concentrate $-0.5+0.2 \mathrm{Mm}$ & 8.00 & 42.07 & 5.55 & 15.74 \\
\hline Concentrate $-0.2+0.02 \mathrm{MM}$ & 1.85 & 39.58 & 8.01 & 3.42 \\
\hline Total concentrate CMc & 12.71 & \multicolumn{2}{|c|}{-} & 25.46 \\
\hline Industrial product & 10.52 & 12.05 & 8.97 & 5.93 \\
\hline Tailings & 33.60 & 2.72 & 4.27 & 4.27 \\
\hline Sludge -0.02MM & 5.70 & 9.30 & 6.11 & 2.48 \\
\hline \multicolumn{5}{|c|}{ Reduction in size - rewashing of industrial product } \\
\hline Industrial product concentrate & 4.55 & 46.05 & 7.20 & 9.80 \\
\hline Industrial product & 10.39 & 21.81 & 6.71 & 10.60 \\
\hline \multicolumn{5}{|c|}{ Acid leaching } \\
\hline Concentrate 1 from solution & 5.81 & 38.53 & 11.18 & 10.47 \\
\hline Concentrate 2 from solution & 1.53 & 29.20 & 14.57 & 2.09 \\
\hline Industrial product & 9.11 & 19.15 & 13.75 & 8.16 \\
\hline Sludge cakes after leaching & 12.87 & 0.76 & 0.59 & 0.46 \\
\hline \multicolumn{5}{|c|}{ Total amount of products: } \\
\hline Concentrate (in mineral form) & 37.08 & 43.00 & 7.92 & 74.57 \\
\hline Concentrate 1 from solution & 5.81 & 38.53 & 11.18 & 10.47 \\
\hline Concentrate 2 from solution & 1.53 & 29.20 & 14.57 & 2.09 \\
\hline Industrial product & 9,11 & 19.15 & 13.75 & 8.16 \\
\hline Sludge cakes after leaching & 12.87 & 0.76 & 0.50 & 0.46 \\
\hline Final tailings & 33.60 & 2.66 & 4.31 & 4.27 \\
\hline Total amount of tailings & 46.47 & 2.17 & 3.25 & 4.71 \\
\hline $\begin{array}{l}\text { Total amount of hematite-braunite } \\
\text { ore }\end{array}$ & 100.00 & 21.38 & 6.66 & 100.00 \\
\hline
\end{tabular}

The acid leaching under the optimal parameters of the process resulted in revealing the possibility of forming manganese concentrates containing 38.53-40.44\% manganese (61.27-66.46 \% $\mathrm{MnO}_{2}$ ) with residual content 0.85-1.45\% $\mathrm{SiO}_{2}$. The obtained concentrates, depending on the purpose, can be subject to chemical cleaning for the purpose of separating 
some additives. The quality improvement of manganese concentrates is the subject of further studies.

The sludge cakes of decomposition of the industrial products contain 80.36-83.81\% $\mathrm{SiO}_{2}$, with calcium and aluminum being their related components, respectively, $\mathrm{CaO}-2-8.5$ $\% ; \mathrm{Al}_{2} \mathrm{O}_{3}-4-5 \%$; magnesium, sodium and potassium are present in small amounts. According to electronic and optical microscopy data, sludge cakes were found to have separate uncovered grains of braunite and tephroite, whose presence is probably conditioned by the incomplete decomposition, as a result of their thin intergrowth with the minerals of hollow rocks.

As a result of acid leaching, $10.47 \%$ manganese containing $38.53 \%$, with the removal of $12.87 \%$ material $\mathrm{n}$ the form of sludge cakes containing $0.76 \% \mathrm{Mn}(\mathrm{tbl})$ was extracted from resistant industrial products of gravitational and magnetic beneficiation of the hematite-braunite ores.

\section{Conclusions}

The performed studies have shown the possibility of acid leaching of resistant industrial products of beneficiation of hematite-braunite ores and extraction of manganese concentrates in the form of sediments containing 38.53-40.44\% manganese $(61.27-66.46 \%$ $\mathrm{MnO} 2$ ) and $10-15 \%$ Fe having residual content $\mathrm{SiO} 2-0.85-1.45 \%$.

The use of hydrometallurgical techniques in combination with the operations of beneficiation allows for the $10.47 \%$ increase of total extraction of manganese in mineral form, and the $76.8-87.19 \%$ increase of it in chemical form.

The suggested combined scheme of processing hematite-braunite ores allows for the complex extraction of valuable components; obtaining manganese concentrates, gold density, and the sludge cakes of acid decomposition (with the content of $80.36-83.81 \%$ $\mathrm{SiO}_{2}$ ) can also be recommended for glass manufacturing.

\section{References}

1. G.I. Arkhipov, Mineral resources of mining industry in the Far East. Strategic evaluation of exploration capabilities, (2017).

2. T.V. Bashlykova, G.A. Pakhomova, B.S. Lagov, A.B. Zhivaeva, T.B. Doroshenko, A.R. Makavetskas, T.O. Shulga, Technological aspects of subsoil use, 241. (2005).

3. N.V. Moiseenko, S.V. Shchipachyov, N.S. Sanilevich, T.B. Makeeva, Geology, mineralogy and geochemistry of precious metals of Eastern Russia: new technologies of processing precious metal raw material, 72. (2005).

4. L.P. Tigunov, E.G. Ozhogina, E.G. Litvintsev, E.S. Bronitskaya, S.I. Anufrieva, E.A. Kalish, Mining journal, 2, 78. (2007).

5. I.Y. Rasskazov, B.G. Saksin, Physical-technical problems of processing of minerals. 1, 13 (2014).

6. M.A. Gurman, L.I. Shcherbak, Physical-technical problems of processing of minerals. 3, 157, (2018).

7. M.A. Gurman, L.I, Shcherbak, Physical-technical problems of processing of minerals, 1, 144, (2018).

8. A.K. Lavrukhina, L.V. Yukina, analytical chemistry of manganese, (1974).

9. Alafara A. Baba, Lateef Ibrahim, Folahan A. Adekola, Rafiu B. Bale, Malay K. Ghosh, Abdul R. Sheik, Sangita R. Pradhan, Olushola S. Ayanda, Ismail O. Folorunsho, Journal of Minerals and Materials Characterization and Engineering, 2, 230 (2014).

10. K.A. Baklanova, O.P, Boyarshinova, Mineral raw material analysis, 350 (1956)

11. Z.E. Golbraich, Practical work on inorganic chemistry (1979). 